\title{
Vanadium(V)/Mandelic Acid Initiated Graft Copolymerization of Acrylamide onto Guar Gum in an Aqueous Medium
}

\author{
Arti Srivastava, Vivek Mishra, Shailendra Kumar Singh, Rajesh Kumar \\ Organic Polymer Research Laboratory, Department of Chemistry, Banaras Hindu University, Varanasi 221005, India
}

Received 24 April 2009; accepted 21 July 2009

DOI 10.1002/app.31172

Published online 14 October 2009 in Wiley InterScience (www.interscience.wiley.com).

\begin{abstract}
The graft copolymerization reaction of acrylamide onto guar gum with a vanadium(V)/mandelic acid redox pair was carried out in an $\mathrm{N}_{2}$ atmosphere. The optimum concentrations of vanadium(V), mandelic acid, hydrogen ions, acrylamide, and guar gum for the maximum percentage of grafting were $6.0 \times 10^{-3}, 2.0 \times 10^{-2}, 55.0 \times$ $10^{-2}$, and $20.0 \times 10^{-2} \mathrm{~mol} / \mathrm{dm}^{3}$ and $110.1 \times 10^{-2} \mathrm{~g} / \mathrm{dm}^{3}$, respectively. The optimum time and temperature of reaction were $90 \mathrm{~min}$ and $35^{\circ} \mathrm{C}$, respectively, and during the study of $\left[\mathrm{H}^{+}\right]$variation, a prompt change in the value of the grafting parameters was observed. The maximum percentage of
\end{abstract}

swelling of the graft copolymer was achieved at room temperature in $1 \mathrm{~h}$. Studies of the flocculation, viscosity, and metal-ion absorption capacity were also performed. The synthesized graft copolymer was characterized by Fourier transform infrared spectroscopy and thermogravimetric analyses, which showed that the grafted guar gum was thermally more stable than the ungrafted guar gum. $\odot 2009$ Wiley Periodicals, Inc. J Appl Polym Sci 115: 2375-2385, 2010

Key words: graft copolymers; synthesis; thermal properties

\section{INTRODUCTION}

Solution graft copolymerization is an enthralling area of research into the modification natural polymers to make biocompatible polymeric materials. ${ }^{1,2}$ The radical-initiated functionalization of polysaccharide has received considerable attention in recent years and has become a useful method for the industrial production of modified polysaccharides. Several studies on the graft copolymerization of various vinyl monomers onto natural polymers have been done to modify various properties of natural polymers, such as hygroscopicity, thermal property, and biodegradability. It has been reported that the grafting of acrylamide $(\mathrm{ACM})^{3}$ onto starch imparted thermal stability, which increased with increasing ACM concentration, and the resulting graft copolymer was used as a retention aid in paper making, a binder between fibers to compensate for the decrease in the strength of filler retention. ${ }^{4}$ The water-retention capacity of cellulose increases after the grafting of $\mathrm{ACM}^{5}$ onto

Correspondence to: R. Kumar (rkr_bhu@yahoo.com).

Contract grant sponsor: Department of Science and Technology (New Delhi, India) through a Young Scientist grant.

Journal of Applied Polymer Science, Vol. 115, 2375-2385 (2010) (C) 2009 Wiley Periodicals, Inc. it, and corn starch-g-ACM has been used in flocculation for the treatment of wastewater containing $\mathrm{Hg}^{2+}$ from industry. ${ }^{6}$ It has been reported ${ }^{7,8}$ that guar gum-g-ACM is a compromise between the high-drag-reduction effectiveness of polyacrylamide (polyACM) and the high shear stability of guar gum.

Guar gum (GOH) is a naturally occurring highmolecular-weight carbohydrate polymer and possesses a rigid and nonionic character. ${ }^{9,10}$ It is a galactomannan similar to locust bean gum, consisting of a $1 \rightarrow 4$-linked $\beta$-D-mannopyranose backbone with branch points from their 6 positions linked to $\alpha$-D-galactose (i.e., $1 \rightarrow 6$-linked- $\alpha$-D-galactopyranose). There are between 1.5 and 2 mannose residues for every galactose residue, which consist of a mannose backbone with a galactose side chain (Structure 1). It has wide range of industrial applications, namely, in the food, ${ }^{11}$ drug, and pharmaceutical industries, ${ }^{12,13}$ because of its water retention-capacity, ${ }^{14}$ high thickening efficiency, ${ }^{15}$ good compatibility, and low cost. However, Whistler ${ }^{16}$ pointed out the drawback of guar gum: that it suffers from a high rate of biodegradability, which limits its application in industry and can be improved by the introduction of some functional groups.

The graft copolymers of different natural substrates have been synthesized by several redox pairs $^{17,18}$ and used in flocculation ${ }^{19}$ and as a 


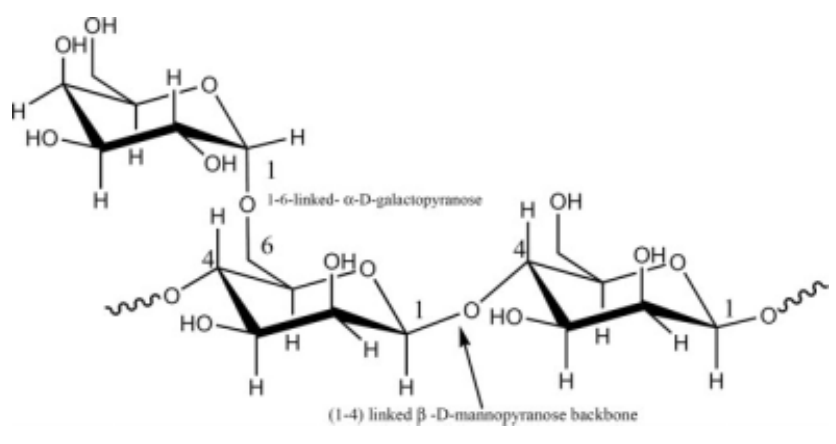

Structure 1 Chemical structure of guar gum.

biodegradable drag-reducing agent, ${ }^{20}$ whereas polyACM finds extensive application in the production of petroleum and has been used in oil recovery during the drilling process, the acidizing of wells, and hydraulic fracturing. PolyACM has been noted for its application in secondary oil recovery, but polyACM is degraded at high shear rates in particularly salty water that contains a significant concentration of divalent cations. However, guar gum is a neutral polysaccharide; therefore, it is stable in salty water and possesses a high shear stability, but it is not as effective a drag reducing agent as polyACM.

A few metal ions, such as $\mathrm{Ce}(\mathrm{IV}),{ }^{7,8} \mathrm{Fe}(\mathrm{II}),{ }^{18}$ and $\mathrm{Cu}(\mathrm{II}),{ }^{21}$ have been applied for the generation of primary free radicals for graft copolymerization; this prompted us to choose vanadium(V) for radical generation, and it was found worthy for the efficient generation of primary free radicals for graft copolymerization, and this system to gives more graft copolymer than homopolymer.

Thus, on the basis of these properties and the industrial utility of guar gum and ACM, an attempt was made to graft ACM onto guar gum with an efficient redox pair, that is, $\mathrm{V}^{+5} /$ mandelic acid (MA) to a achieve maximum percentage of grafting over the homopolymer. During radical graft copolymerization, primary free radicals are incorporated into the grafted chain, which makes them more potent and functional. Such modification yields a monomergrafted substrate, which substantially changes the reactivity of the polymers. Applications of modified guar gum with polyACM are usually based on the enhancement of polar pendant groups, such as amide and acid groups. ${ }^{22}$

\section{EXPERIMENTAL}

\section{Materials}

ACM (Aldrich, St. Louis, MO) was recrystallized twice from methanol and dried in vacuo. Ammonium metavanadate and MA were received from Merck (Mumbai, India) and used as received. Sulfuric acid and methanol were also from Merck and were used as received. Guar gum was purchased from Sigma and were used as received.

\section{Synthesis of the graft copolymer}

Guar gum solution was prepared by the addition of $91.7 \times 10^{-2} \mathrm{~g} / \mathrm{dm}^{3}$ gum to $100 \mathrm{~mL}$ of triple-distilled water in a three-necked reactor and kept in a thermostated oven at $35^{\circ} \mathrm{C}$. MA $\left(2.0 \times 10^{-3} \mathrm{~mol} / \mathrm{dm}^{3}\right)$, ACM $\left(20.0 \times 10^{-2} \mathrm{~mol} / \mathrm{dm}^{3}\right)$, and sulfuric acid solutions $\left(35.0 \times 10^{-2} \mathrm{~mol} / \mathrm{dm}^{3}\right)$ were added to the gum solution. A stream of nitrogen gas was passed into the solution of the reaction mixture and into the solution of vanadium $(\mathrm{V})$ separately. After a desired interval of time, the reaction was initiated by the addition of the solution of vanadium $(\mathrm{V})\left(10.0 \times 10^{-3}\right.$ $\mathrm{mol} / \mathrm{dm}^{3}$ ) into the reaction mixture. The reaction was allowed to continue for $120 \mathrm{~min}$; after that, the reaction mixture was poured into a methanol-water mixture. The graft copolymer precipitated out, whereas the polyACM remained in the filtrate. The graft copolymer was separated by filtration and washed with a methanol-water mixture (two times) so that any homopolymer stuck in the graft copolymer passed into the filtrate. The graft copolymer thus obtained was dried and weighed, and the values of the grafting parameters were obtained as follows: percentage grafting ratio $(\% G)=138 \%$, percentage grafting efficiency $(\% E)=60 \%$, percentage conversion $(\% C)=13.8$, percentage add-on $(\% A)=$ 58.1 , rate of grafting $\left(R_{g}\right)=26.9 \times 10^{-7} \mathrm{~mol} \mathrm{~L}^{-1} \mathrm{~s}^{-1}$, percentage swelling $\left(P_{S}\right)=451 \%$, and swelling ratio $\left(S_{R}\right)=4.51$.

\section{Separation of the homopolymer}

For the separation of the homopolymer from the filtrate, a pinch of hydroquinone $(\approx 20 \mathrm{mg}$ in $\approx 50$ $\mathrm{mL}$ of filtrate) was added to the filtrate and concentrated by distillation under reduced pressure. Thereafter, it was poured into an excess of methanol. Thus, polyACM precipitated out; this was filtered, dried, and weighed [percentage homopolymer $(\% H)=40 \%]$.

\section{Determination of the grafting parameters}

The grafting parameters were calculated according to Fanta's definition ${ }^{23}$ in terms of $\% G, \% E, \% A, \% C$, and $\% H$ :

$$
\begin{gathered}
(\% G)=\frac{\text { Weight of grafted polymer }}{\text { Weight of substrate }} \times 100 \\
(\% A)=\frac{\text { Weight of synthetic polymer }}{\text { Weight of graft copolymer }} \times 100
\end{gathered}
$$




$$
\begin{gathered}
(\% C)=\frac{\text { Weight of polymer formed }}{\text { Weight of monomer charged }} \times 100 \\
(\% E)=\frac{\text { Weight of polymerin graft }}{\text { Weight of polymer formed }} \times 100
\end{gathered}
$$

$$
(\% H)=100-\% E
$$

$R_{g}$ was calculated according to following formula ${ }^{24}$ :

$$
\begin{array}{r}
\left(R_{g}\right)=\frac{\text { Weight of grafted polymer }}{\text { Volume } \times \text { Time } \times \text { Molecular Weight of ACM }} \\
\qquad \times 1000\left(\mathrm{~mol} \mathrm{~L}^{-1} \mathrm{~s}^{-1}\right)
\end{array}
$$

The weight of the grafted polymer was the weight of the grafted gum minus the weight of the ungrafted gum.

\section{Characterization of guar gum-g-ACM}

Fourier transform infrared (FTIR) spectra

We recorded the FTIR spectra of the samples by making pellets in $\mathrm{KBr}$ using a Varian Excalibur 3000 (Palo Alto, CA). The sample whose percentage grafting was 138 was taken for FTIR spectrum recording. The FTIR spectral analysis was used to prove the grafting.

\section{Thermogravimetric analysis}

The thermal behavior of guar gum and guar gum-gACM was recorded on a Netzsch-Gerätebäu GmbH (Wittersbacherstrasse, Germany) thermal analyzer within the temperature range $0-900^{\circ} \mathrm{C}$ in an $\mathrm{N}_{2}$ atmosphere at a heating rate of $10^{\circ} \mathrm{C} / \mathrm{min}$. The sample whose $\% G$ was 138 was taken for thermal analysis.

\section{Study of the properties}

Swelling

The swelling behavior of the graft copolymer was examined in water for $1 \mathrm{~h}$; different samples of the graft copolymer were prepared by variation of the concentration of ACM from 5.0 to $40.0 \times 10^{-2} \mathrm{~mol} /$ $\mathrm{dm}^{3}$. We carried out these studies by taking $0.05 \mathrm{~g}$ of the graft copolymer sample in $10 \mathrm{~mL}$ of triple-distilled water and keeping it undisturbed for $1 \mathrm{~h}$. We removed the surface water on the swollen graft copolymer by safely pressing it between the folds of tissue paper; an increased in the weight was recorded. $P_{S}$ and $S_{R}$ were calculated with the following expressions, ${ }^{25}$ and the results are shown later in Figure 4:

$$
\begin{aligned}
& P_{S}= \\
& \text { Weight of swollen polymer - weight of dry polymer } \\
& \text { Weight of dry polymer } \\
& \times 100 \quad(7) \\
& S_{R}= \\
& \text { Weight of swollen polymer - weight of dry polymer } \\
& \text { Weight of dry polymer } \\
& \times 100
\end{aligned}
$$

Absorption of the metal ions

The metal-ion sorption studies were carried out on graft copolymers of different compositions, which were synthesized by the variation of the concentration of ACM from $5 \times 10^{-2}$ to $40 \times 10^{-2} \mathrm{~mol} / \mathrm{dm}^{3}$. For this, $0.01 \mathrm{~g}$ of graft copolymer was placed in a 5 -mL solution of a metal ion of known concentration and kept for $24 \mathrm{~h}$. The strength of the unabsorbed metal solution was determined by a standard method. For the metal-ion sorption studies, we chose five metal ions: $\mathrm{Cu}^{2+}, \mathrm{Ni}^{2+}, \mathrm{Zn}^{2+}, \mathrm{Pb}^{2+}$, and $\mathrm{Hg}^{2+}$. The sorption behavior of the polymeric backbone and graft copolymer for five metals ions was investigated with a reported method. ${ }^{26,27}$

\section{Flocculation}

In a 1-L beaker, $200 \mathrm{~mL}$ of a $1 \%$ weight coal suspension was taken. The beaker was placed on a flocculator (Sonar Jar Set Digital Apparatus, New Delhi, India) with the stirrer blade dipped in the suspension. At $100 \mathrm{rpm}$ of stirring, the required quantity of polymer solution was added to the beaker to make a predetermined dose with respect to the suspension volume. After the addition of polymer solution, the suspension was stirred at a constant speed for $15 \mathrm{~min}$. The flocs were allowed to settle down for $1 \mathrm{~h}$. Clean supernatant liquid was drawn from a depth of $1.0 \mathrm{~cm}$, and its turbidity was measured with a digital Nephelometer (Eutech Instruments Digital Turbidity meter TN-100 Supplied by Merck India) to determine the turbidity in nephelometric units (NTUs).

\section{Intrinsic and absolute viscosity}

The viscosity measurements of the aqueous solutions of guar gum and the graft copolymers (GOH- $g$-polyACM) were carried out with the help of an Ubbelohde ASTM standard viscometer (PISCO, Kolkata, India) at $27 \pm 0.1^{\circ} \mathrm{C}$, as reported earlier by Nayak and Singh. ${ }^{28}$

\section{RESULTS AND DISCUSSION}

To determine the optimum conditions for the grafting of $\mathrm{ACM}$ onto guar gum with $\mathrm{V}^{5+} / \mathrm{MA}$ as the 
TABLE I

Effect of the Vanadium(V) Concentration

\begin{tabular}{rrrrrrr}
\hline $\begin{array}{c}{\left[\mathrm{V}^{5+}\right] \times 10^{3}} \\
\left(\mathrm{~mol} / \mathrm{dm}^{3}\right)\end{array}$ & $\% G$ & $\% A$ & $\% \mathrm{C}$ & $\% E$ & $\% H$ & $\begin{array}{c}R_{g} \times 10^{7} \\
\left(\mathrm{~mol} \mathrm{~L}^{-1} \mathrm{~s}^{-1}\right)\end{array}$ \\
\hline 6.0 & 197.0 & 77.8 & 17.6 & 72.1 & 27.9 & 38.2 \\
8.0 & 162.5 & 61.8 & 15.6 & 67.0 & 33.0 & 31.5 \\
10.0 & 138.2 & 58.1 & 13.8 & 60.0 & 40.0 & 26.9 \\
15.0 & 82.7 & 45.3 & 11.8 & 30.5 & 69.5 & 16.1 \\
25.0 & 26.1 & 17.3 & 7.0 & 17.5 & 82.5 & 5.0 \\
\hline
\end{tabular}

$[\mathrm{MA}]=2.0 \times 10^{-3} \mathrm{~mol} / \mathrm{dm}^{3} ;\left[\mathrm{H}^{+}\right]=35.0 \times 10^{-2} \mathrm{~mol} / \mathrm{dm}^{3} ;[\mathrm{GOH}]=91.7 \times$ $10^{-2} \mathrm{~g} / \mathrm{dm}^{3} ;[\mathrm{ACM}]=20.0 \times 10^{-2} \mathrm{~mol} / \mathrm{dm}^{3}$; time $=120 \mathrm{~min}$; temperature $=$ $35^{\circ} \mathrm{C}$.

redox initiator, graft copolymerization was carried out under various reaction times, temperatures, and concentrations of vanadium ions, MA, guar gum, hydrogen ions, and monomer.

\section{Effects of the variables on the grafting parameters}

The effect of the variable variation on the grafting parameters $\left(\% G, \% E, \% A, \% C, \% H\right.$, and $\left.R_{g}\right)$ were studied and are described in detail either by plots of the graphs between the grafting parameters and variables or in tables.

Effect of the vanadium $(\mathrm{V})$ concentration

The concentration of vanadium was varied from 6.0 to $25.0 \times 10^{-3} \mathrm{~mol} / \mathrm{dm}^{3}$ to study its effect on $\% G$, $\% E, \% A, \% C, \% H$, and $R_{g}$, and the findings are summarized in Table I. The grafting parameters for ACM onto guar gum decreased with increasing vanadium ion concentration. The decrease in the values of grafting parameters was due to the following reasons:

1. At higher concentrations of vanadium $(\mathrm{V})$, the oxidative termination of the primary free radical led to a decrease in the grafting parameters:

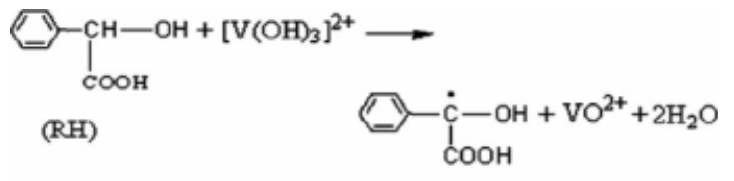

(R)

$$
\mathrm{R}^{\bullet}+\mathrm{V}^{5+} \longrightarrow \text { Oxidation product }+\mathrm{V}^{4+}
$$

2. The homopolymerization over grafting.

It was evident from the results that the enhancement in homopolymer formation was major reason for the decrease in the grafting parameters. Therefore, a second one may be a better explanation for the decrease in grafting parameters.

Effect of the MA concentration

The effect of MA on the grafting parameters was studied by variation of the concentration of MA from 2.0 to $12.5 \times 10^{-2} \mathrm{~mol} / \mathrm{dm}^{3}$. All of the grafting parameters decreased continuously in a gradual manner with increasing concentration of MA, except for the homopolymer, which showed the opposite trend, whereas the conversion increased up to $7.5 \times$ $10^{-2} \mathrm{~mol} / \mathrm{dm}^{3}$. After that, it decreased (Table II).

TABLE II

Effect of the MA Concentration

\begin{tabular}{ccccccc}
\hline $\begin{array}{r}{[\mathrm{MA}] \times 10^{3}} \\
\left(\mathrm{~mol} / \mathrm{dm}^{3}\right)\end{array}$ & $\% G$ & $\% A$ & $\% \mathrm{C}$ & $\% E$ & $\% H$ & $\begin{array}{c}R_{g} \times 10^{7} \\
\left(\mathrm{~mol} \mathrm{~L}^{-1} \mathrm{~s}^{-1}\right)\end{array}$ \\
\hline 2.0 & 138.2 & 58.8 & 13.8 & 60.0 & 40.0 & 26.9 \\
5.0 & 123.6 & 55.2 & 15.6 & 50.4 & 49.6 & 24.1 \\
7.5 & 87.2 & 46.6 & 17.2 & 32.3 & 64.0 & 16.4 \\
10.0 & 50.2 & 33.4 & 16.9 & 20.9 & 79.1 & 9.8 \\
12.5 & 35.0 & 26.0 & 16.5 & 14.9 & 85.1 & 6.8 \\
\hline
\end{tabular}

$\left[\mathrm{V}^{5+}\right]=10.0 \times 10^{-3} \mathrm{~mol} / \mathrm{dm}^{3} ;\left[\mathrm{H}^{+}\right]=35.0 \times 10^{-2} \mathrm{~mol} / \mathrm{dm}^{3} ;[\mathrm{GOH}]=91.7 \times$ $10^{-2} \mathrm{~g} / \mathrm{dm}^{3}$; $[\mathrm{ACM}]=20.0 \times 10^{-2} \mathrm{~mol} / \mathrm{dm}^{3}$; time $=120 \mathrm{~min}$; temperature $=$ $35^{\circ} \mathrm{C}$. 
TABLE III

Effect of the ACM Concentration

\begin{tabular}{crrrrrr}
\hline $\begin{array}{c}\mathrm{ACM} \times 10^{2} \\
\left(\mathrm{~mol} / \mathrm{dm}^{3}\right)\end{array}$ & $\% G$ & $\% A$ & $\% C$ & $\% E$ & $\% H$ & $\begin{array}{c}R_{g} \times 10^{7} \\
\left(\mathrm{~mol} \mathrm{~L}^{-1} \mathrm{~s}^{-1}\right)\end{array}$ \\
\hline 5.0 & 80.0 & 44.4 & 23.8 & 53.3 & 46.7 & 15.6 \\
10.0 & 109.3 & 52.2 & 27.0 & 55.0 & 44.0 & 17.3 \\
20.0 & 138.2 & 58.8 & 13.8 & 60.0 & 40.0 & 26.9 \\
30.0 & 90.5 & 47.7 & 17.9 & 33.2 & 66.8 & 17.6 \\
40.0 & 21.8 & 11.6 & 3.9 & 18.0 & 82.0 & 3.9 \\
\hline
\end{tabular}

$\left[\mathrm{V}^{5+}\right]=10.0 \times 10^{-3} \mathrm{~mol} / \mathrm{dm}^{3} ;[\mathrm{MA}]=2.0 \times 10^{-3} \mathrm{~mol} / \mathrm{dm}^{3} ;\left[\mathrm{H}^{+}\right]=35.0 \times 10^{-2}$ $\mathrm{mol} / \mathrm{dm}^{3} ;[\mathrm{GOH}]=91.7 \times 10^{-2} \mathrm{~g} / \mathrm{dm}^{3} ;$ time $=120 \mathrm{~min}$; temperature $=35^{\circ} \mathrm{C}$.

This behavior was due to a greater formation of the homopolymer than the graft copolymer, and the increased value of the homopolymer supported this fact.

\section{Effect of the ACM concentration}

Table III reveals that when the concentration of ACM was varied from 5.0 to $40.0 \times 10^{-2} \mathrm{~mol} / \mathrm{dm}^{3}$, $\% G, \% E, \% A$, and $R_{g}$ increased, but $\% H$ decreased up to $20.0 \times 10^{-2} \mathrm{~mol} / \mathrm{dm}^{3}$. Beyond this concentration, $\% G, \% E, \% A$, and $R_{g}$ decreased. However, the conversion increased as the concentration of ACM increased up to $10 \times 10^{-2} \mathrm{~mol} / \mathrm{dm}^{3}$. The increments in $\% G, \% E, \% A$, and $R_{g}$ were due to the greater availability of ACM at the close proximity of the polymer backbone. The monomer molecule at the close proximity of the reaction site became an acceptor of the guar gum radicals, which resulted in chain initiation. Thereafter, the monomer molecule became a free-radical donor to the neighboring molecules; in this way, the grafted chains grew. The decrease in $\% G, \% E, \% A$, and $R_{g}$ were explained in terms of an increase in the viscosity of the reaction medium due to the preferential formation of poly$\mathrm{ACM}$ at higher concentrations of monomer.
Effect of the hydrogen-ion concentration

The graft copolymerization was carried out at different concentrations of hydrogen ion (Table IV). With increasing hydrogen-ion concentration from 16.0 to $55.0 \times 10^{-2} \mathrm{~mol} / \mathrm{dm}^{3}, \% G, \% C, \% E, \% A$, and $R_{g}$ increased promptly up to a $35.0 \times 10^{-2} \mathrm{~mol} / \mathrm{dm}^{3}$ concentration of hydrogen ions; after that, the grafting parameters increased gradually. Thus, from these results, we concluded that hydrogen ions played an important role with this redox pair. The increment in the grafting parameters could be explained on the basis of fact that in the aqueous solution, vanadium $(\mathrm{V})$ existed as $\mathrm{VO}^{2+}$, but in the acidic medium, vanadium $(\mathrm{V})$ existed in many species, and with increasing hydrogen-ion concentration, it reacted with these ions to give $\left[\mathrm{V}(\mathrm{OH})_{3}\right]^{2+}$, which was a better oxidant. ${ }^{29}$ Hence, the species $\left[\mathrm{V}(\mathrm{OH})_{3}\right]^{2+}$ reacted with MA and produced primary free radicals at a faster rate. Thus, on increasing hydrogen-ion concentration, the formation of primary free radicals increased; thereby, the grafting parameters also increased:

$$
\mathrm{VO}_{2}^{+}+\mathrm{H}_{3} \mathrm{O}^{+} \rightarrow\left[\mathrm{V}(\mathrm{OH})_{3}\right]^{2+}
$$

TABLE IV

Effect of the Hydrogen-Ion Concentration

\begin{tabular}{crrrrrr}
\hline $\begin{array}{c}{\left[\mathrm{H}^{+}\right] \times 10^{2}} \\
\left(\mathrm{~mol} / \mathrm{dm}^{3}\right)\end{array}$ & $\% G$ & $\% A$ & $\% \mathrm{C}$ & $\% E$ & $\% H$ & $\begin{array}{c}R_{g} \times 10^{7} \\
\left(\mathrm{~mol} \mathrm{~L}^{-1} \mathrm{~s}^{-1}\right)\end{array}$ \\
\hline 16.0 & 11.1 & 8.0 & 9.8 & 7.6 & 92.4 & 2.1 \\
24.0 & 30.5 & 23.7 & 10.5 & 18.7 & 81.3 & 5.9 \\
35.0 & 138.2 & 58.2 & 13.8 & 60.0 & 40.0 & 29.6 \\
46.0 & 155.4 & 60.1 & 14.3 & 65.5 & 34.5 & 30.3 \\
55.0 & 168.4 & 62.8 & 16.1 & 67.4 & 32.6 & 32.8 \\
\hline
\end{tabular}

$\left[\mathrm{V}^{5+}\right]=10.0 \times 10^{-3} \mathrm{~mol} / \mathrm{dm}^{3} ;[\mathrm{MA}]=2.0 \times 10^{-3} \mathrm{~mol} / \mathrm{dm}^{3} ;[\mathrm{ACM}]=20.0 \times 10^{-2}$ $\mathrm{mol} / \mathrm{dm}^{3} ;[\mathrm{GOH}]=91.7 \times 10^{-2} \mathrm{~g} / \mathrm{dm}^{3} ;$ time $=120 \mathrm{~min}$; temperature $=35^{\circ} \mathrm{C}$. 


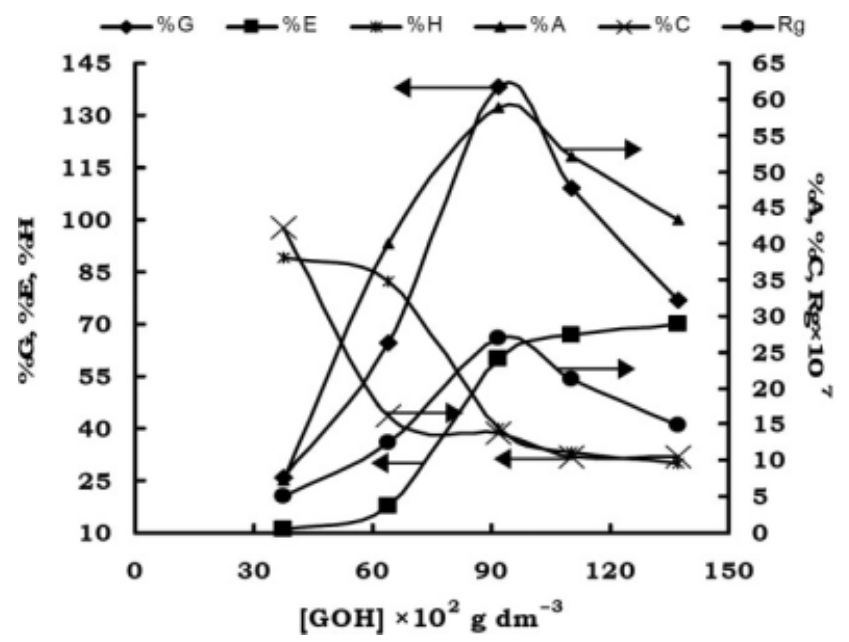

Figure 1 Effect of the guar gum concentration $\left(\left[\mathrm{V}^{5+}\right]=\right.$ $10.0 \times 10^{-3} \mathrm{~mol} / \mathrm{dm}^{3} ;[\mathrm{MA}]=2.0 \times 10^{-3} \mathrm{~mol} / \mathrm{dm}^{3} ;\left[\mathrm{H}^{+}\right]$ $=35.0 \times 10^{-2} \mathrm{~mol} / \mathrm{dm}^{3} ;[\mathrm{ACM}]=20.0 \times 10^{-2} \mathrm{~mol} / \mathrm{dm}^{3}$; time $=120 \mathrm{~min}$; temperature $=35^{\circ} \mathrm{C}$ ).

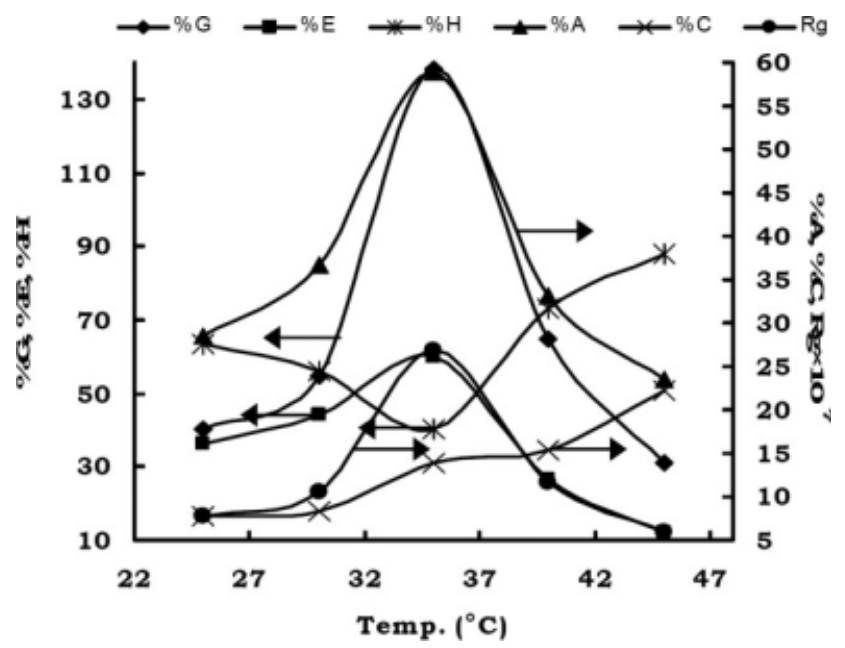

Figure 3 Effect of temperature $\left(\left[\mathrm{V}^{5+}\right]=10.0 \times 10^{-3} \mathrm{~mol} /\right.$ $\mathrm{dm}^{3} ;[\mathrm{MA}]=2.0 \times 10^{-3} \mathrm{~mol} / \mathrm{dm}^{3} ;\left[\mathrm{H}^{+}\right]=35.0 \times 10^{-2}$ $\mathrm{mol} / \mathrm{dm}^{3} ;[\mathrm{ACM}]=20.0 \times 10^{-2} \mathrm{~mol} / \mathrm{dm}^{3} ;[\mathrm{GOH}]=91.7$ $\times 10^{-2} \mathrm{~g} / \mathrm{dm}^{3}$; time $\left.=120 \mathrm{~min}\right)$.

$$
\mathrm{RM}^{\bullet}+\mathrm{GOH} \rightarrow \mathrm{GO}^{\bullet}+\mathrm{RMH}
$$

As the concentration of guar gum further increased, $\% G, \% A, \% C, \% H$, and $R_{g}$ decreased, whereas $\% E$ increased. This behavior could be explained on the ground that the viscosity of the reaction medium increased with increasing guar gum concentration, which hindered the movement of free radicals; therefore, decreases in $\% G, \% A$, and $R_{g}$ were observed.

\section{Effect of the time}

The graft copolymerization reaction was carried out in intervals of time, that is, from 60 to $180 \mathrm{~min}$, to study the effect of time duration of reaction on the grafting parameters and $R_{g}$ (Fig. 2). $\% G, \% A, \% E$,

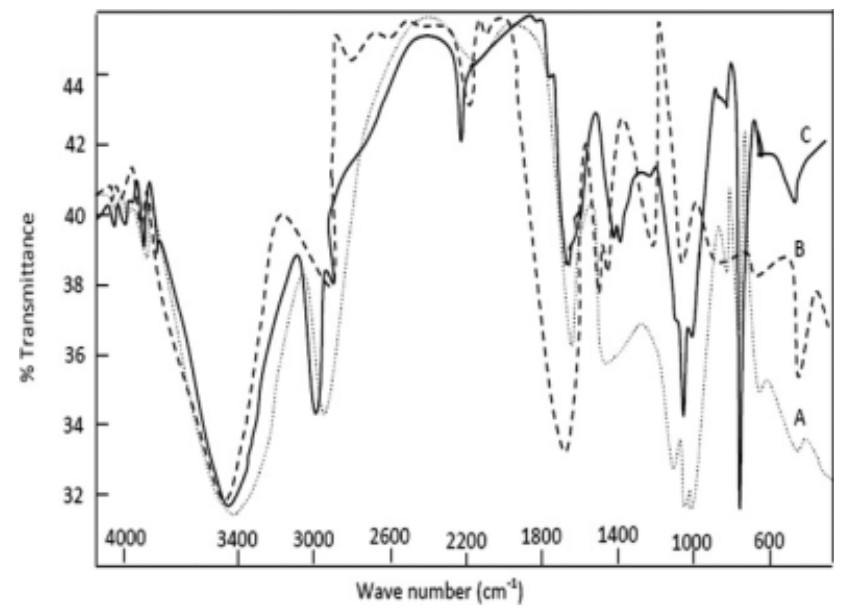

Figure 4 Traces of FTIR spectra of (A) guar gum, (B) polyACM, and (C) guar gum- $g$-ACM.
Figure 2 Effect of time $\left(\left[\mathrm{V}^{5+}\right]=10.0 \times 10^{-3} \mathrm{~mol} / \mathrm{dm}^{3}\right.$; $[\mathrm{MA}]=2.0 \times 10^{-3} \mathrm{~mol} / \mathrm{dm}^{3} ;\left[\mathrm{H}^{+}\right]=35.0 \times 10^{-2} \mathrm{~mol} /$ $\mathrm{dm}^{3} ;[\mathrm{ACM}]=20.0 \times 10^{-2} \mathrm{~mol} / \mathrm{dm}^{3} ;[\mathrm{GOH}]=91.7 \times$ $10^{-2} \mathrm{~g} / \mathrm{dm}^{3}$; temperature $=35^{\circ} \mathrm{C}$ ).

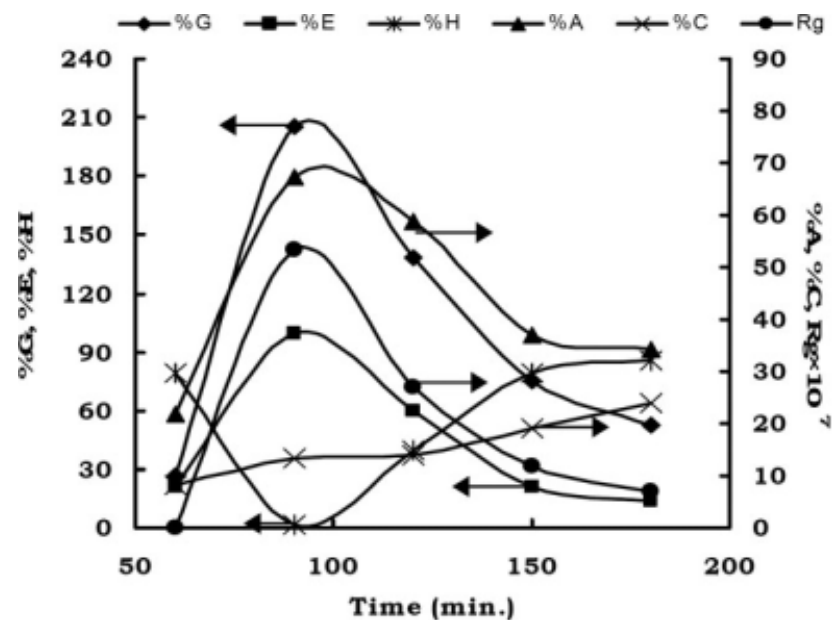

Journal of Applied Polymer Science DOI 10.1002/app 


$$
\begin{aligned}
& \mathrm{VO}_{2}^{+}+\mathrm{H}_{3} \mathrm{O}^{+} \rightarrow\left[\mathrm{V}(\mathrm{OH})_{3}\right]^{2+}
\end{aligned}
$$

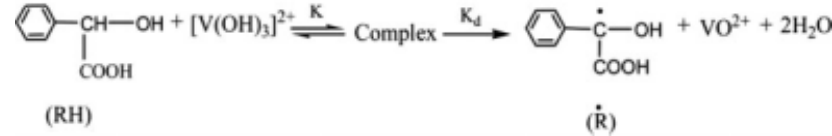

Scheme 1 Formation of the primary free radical. $\mathrm{K}$ and $\mathrm{K}_{\mathrm{d}}$ are rate constant for formation of complex and dissociation of complex respectively.

and $R_{g}$ increased but the homopolymer decreased as the time period of the reaction increased up to $90 \mathrm{~min}$. The increase in grafting parameters was due to a greater and greater addition of monomer molecules to the growing grafted chains. However, with further increases in time, $\% G, \% A, \% E$, and $R_{g}$ decreased and the homopolymer increased. This was due to the lower availability of radicals of the growing grafted chain $\left(\mathrm{GOMn}^{\bullet}\right)$ because of the giant size and an increase in the viscosity of the medium, although the primary free radicals that were formed transferred the electron to the monomer, which produced more homopolymer. This was reflected in the total increased $\% C$. The conversion of the monomer to polymer increased continuously with increasing time from 60 to $180 \mathrm{~min}$.

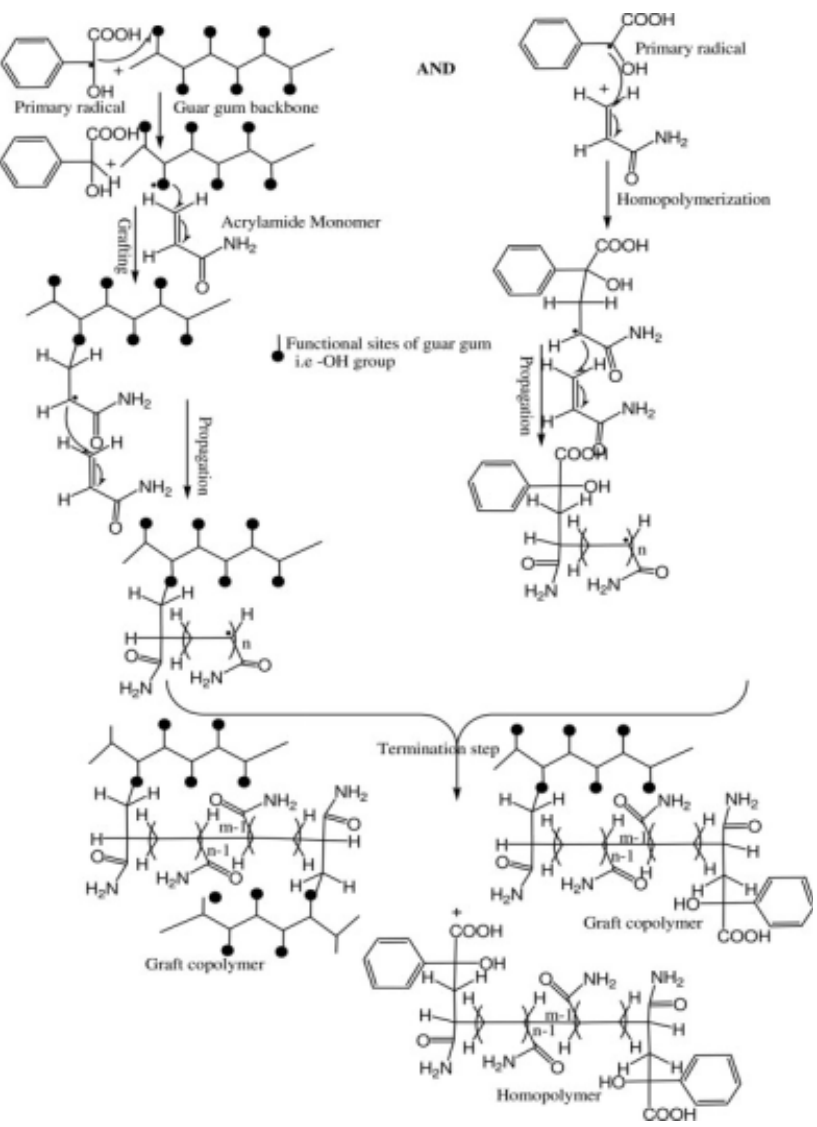

Scheme 2 Graft copolymerization and simultaneous formation of the homopolymer.

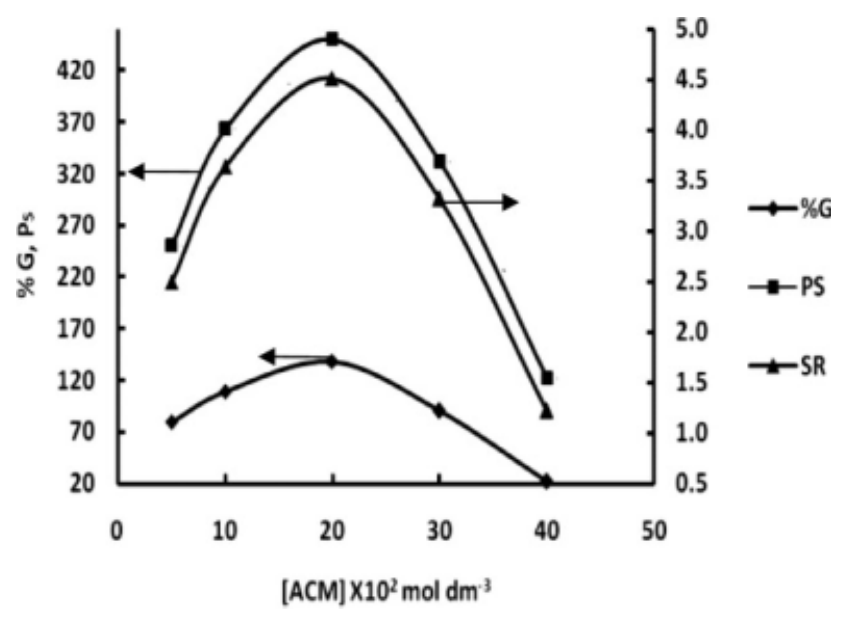

Figure 5 Swelling behavior $\left(\left[\mathrm{V}^{5+}\right]=10.0 \times 10^{-3} \mathrm{~mol} /\right.$ $\mathrm{dm}^{3} ;[\mathrm{MA}]=2.0 \times 10^{-3} \mathrm{~mol} / \mathrm{dm}^{3} ;\left[\mathrm{H}^{+}\right]=35.0 \times 10^{-2}$ $\mathrm{mol} / \mathrm{dm}^{3} ;[\mathrm{GOH}]=91.7 \times 10^{-2} \mathrm{~g} / \mathrm{dm}^{3} ;$ time $=120 \mathrm{~min}$; temperature $=35^{\circ} \mathrm{C}$ ).

\section{Effect of the temperature}

The grafting reaction was carried out at various temperatures ranging from 25 to $45^{\circ} \mathrm{C}$ (Fig. 3). With increasing temperature from 25 to $35^{\circ} \mathrm{C}, \% G, \% A$, $\%$, $\% E$, and $R_{g}$ increased, but the homopolymer decreased. This effect could be explained as follows: (1) the rate of production of primary free radicals increased, and (2) the rate of diffusion of ACM onto the guar gum matrix increased with increasing temperature. A similar explanation was given by Samal and coworkers in the grafting of ACM on to nylon $6^{30}$ and silk fibers ${ }^{31}$ However, with further increasing temperature beyond $35^{\circ} \mathrm{C}, \% \mathrm{G}, \% E, \% A$, and $R_{g}$ decreased. The total conversion increased with increasing temperature from 25 to $45^{\circ} \mathrm{C}$, and this may have been due to the formation of a large quantity of homopolymer.

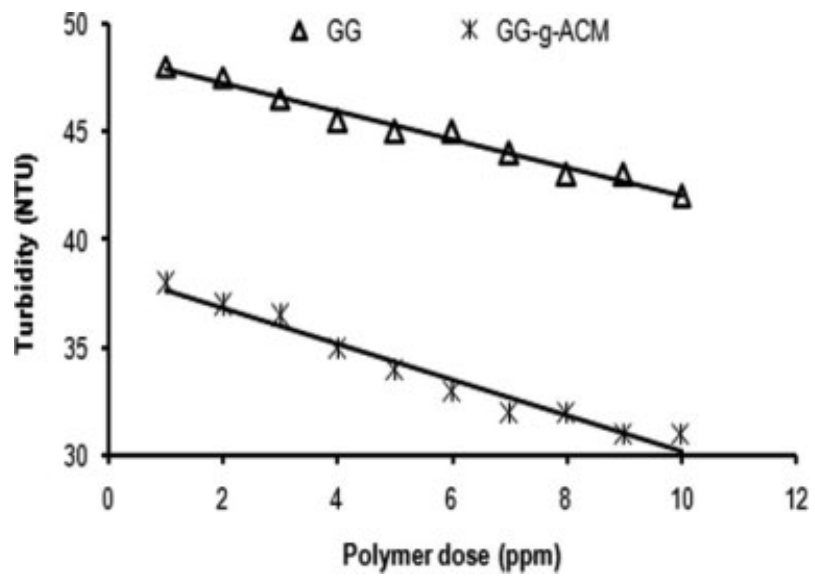

Figure 6 Effect of the polymer dose on the turbidity for noncoking coal (GG = guar gum; GG-g-ACM = guar gum-g-acrylamide). 
TABLE V

Molecular Weights of the Grafted Gum and Pure Gum

\begin{tabular}{lccrrrc}
\hline \multicolumn{1}{c}{ Substrate } & Viscosity & $\log M_{n}$ & \multicolumn{1}{c}{$M_{n}$} & $\log M_{w}$ & \multicolumn{1}{c}{$M_{w}$} & $\begin{array}{c}\text { Polydispersity } \\
\text { index }\left(M_{w} / M_{n}\right)\end{array}$ \\
\hline GOH & 2.3 & 5.35 & 223,872 & 5.70 & 501,187 & 2.24 \\
GOH-g-ACM-1 & 6.2 & 6.00 & $1,000,000$ & 6.24 & $1,737,800$ & 1.74 \\
GOH-g-ACM-2 & 7.2 & 6.10 & $1,259,000$ & 6.34 & $2,188,000$ & 1.74 \\
GOH-g-ACM-3 & 8.2 & 6.18 & $1,514,000$ & 6.39 & $2,455,000$ & 1.62 \\
GOH-g-ACM-4 & 6.7 & 6.05 & $1,122,000$ & 6.28 & $1,905,000$ & 1.70 \\
GOH-g-ACM-5 & 4.1 & 5.73 & 537,000 & 6.02 & $1,047,000$ & 1.95 \\
\hline
\end{tabular}

\section{Evidence of grafting}

The guar gum spectrum [Fig. 4(A)] showed a band at $2909 \mathrm{~cm}^{-1}$ due to $\mathrm{C}-\mathrm{H}$ stretching vibrations. The bands at 1420 and $1300 \mathrm{~cm}^{-1}$ were assigned to $-\mathrm{CH}_{2}$ scissoring and $-\mathrm{OH}$ bending vibrations, respectively. The band at $1080 \mathrm{~cm}^{-1}$ was due to $\mathrm{CH}-\mathrm{O}-\mathrm{CH}_{2}$ stretching. In the case of polyACM [Fig. 4(B)], a broad absorption band at $3430 \mathrm{~cm}^{-1}$ was due to $\mathrm{N}-\mathrm{H}$ stretching. Two strong bands at 1660 and $1620 \mathrm{~cm}^{-1}$ were due to amide $\mathrm{I}\left({ }_{\mathrm{v}} \mathrm{C}=\mathrm{O}\right.$ stretching) and amide II ( $\mathrm{N}-\mathrm{H}$ bending). The bands at 1400 and $2970 \mathrm{~cm}^{-1}$ were due to $\mathrm{C}-\mathrm{N}$ and $\mathrm{C}-\mathrm{H}$ stretching vibrations. Other bands at 1460 and 1300 $\mathrm{cm}^{-1}$ were attributed to $\mathrm{CH}_{2}$ scissoring and $\mathrm{CH}_{2}$ twisting. The presence of a broad absorption band [Fig. $4(\mathrm{C})$ ] at $3410 \mathrm{~cm}^{-1}$ was due to the overlap of the $-\mathrm{OH}$ stretching band of $\mathrm{GOH}$ and the $-\mathrm{NH}$ stretching band of polyACM. The band at $1656 \mathrm{~cm}^{-1}$ was due to the amide I band of the amide group of polyACM. The band at $1600 \mathrm{~cm}^{-1}$ of $\mathrm{GOH}$ and the amide II band of polyACM overlapped with each other and led to the broad band at $1640 \mathrm{~cm}^{-1}$. The presence of the band at $1780 \mathrm{~cm}^{-1}$ was due to free

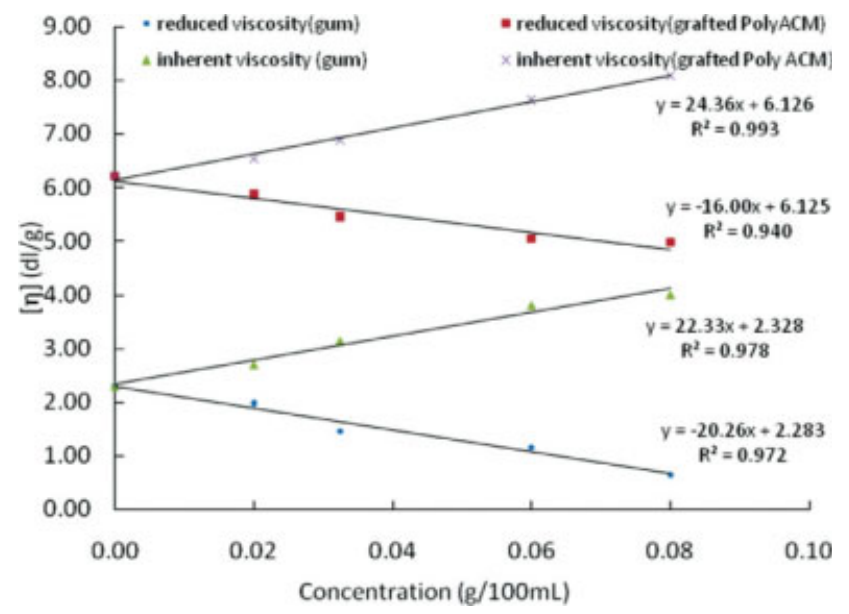

Figure 7 Curves of the reduced/inherent viscosity versus the concentration of guar gum and grafted polyACM for the measurement of [ $\eta$ ]. [Color figure can be viewed in the online issue, which is available at www.interscience. wiley.com.] acid groups of the primary free radical, which was incorporated into the grafted chain. These bands of GOH-g-polyACM were also present separately in the GOH and polyACM spectra at different frequencies. When polyACM was removed from the graft copolymer, the presence of these bands in the graft copolymer supported the strong evidence of grafting.

\section{Mechanism}

The following mechanism was predicted for the reaction containing guar gum $(\mathrm{GOH}), \mathrm{MA}$, vanadium, ACM, and hydrogen ions. MA (RH) reacted with vanadium to give $R^{\bullet}$ radical (Scheme 1 ). This radical abstracted hydrogen atoms from the guar gum molecule to produce guar gum macroradicals $\left(\mathrm{GO}^{\bullet}\right)$. The monomer radicals, which were in close proximity to the reaction sites, became acceptors of the guar gum radicals; this resulted in chain initiation. Thereafter, they became free-radical donors to neighboring molecules. In this way, the grafted chain propagated. These grafted chains terminated by coupling to give graft the copolymer, as shown in Scheme 2.

\section{Characterization and studies}

Swelling study

The effect of the swelling behavior on $\% G$ was studied by variation of the concentration of ACM from 5.0 to $40.0 \times 10^{-2} \mathrm{~mol} / \mathrm{dm}^{3}$ (Fig. 5). $P_{S}$ and $S_{R}$ of the graft copolymer increased with increasing $\% G$. This behavior could be explained on the basis of fact that ACM was hydrophilic in nature. ${ }^{32}$ The increasing percentage of the polyACM chain on to guar gum provided more hydrophilicity to the graft copolymer, and thereby, increases in $P_{S}$ and $S_{R}$ were observed.

\section{Flocculation study}

The flocculation efficiencies of the guar gum backbone and the graft copolymer of polyACM were 
TABLE VI

Absorption Studies of Metal Ions on Guar Gum and Guar Gum-g-ACM

\begin{tabular}{|c|c|c|c|c|c|c|c|c|c|c|c|c|c|c|c|c|c|}
\hline \multirow[b]{2}{*}{ Sample } & \multirow{2}{*}{$\begin{array}{c}{[\mathrm{ACM}]} \\
\times 10^{2} \\
\left(\mathrm{~mol} / \mathrm{dm}^{3}\right)\end{array}$} & \multirow[b]{2}{*}{$\% G$} & \multicolumn{5}{|c|}{ Percent uptake } & \multicolumn{5}{|c|}{ Partition coefficient } & \multicolumn{5}{|c|}{ Retention capacity } \\
\hline & & & $\mathrm{Cu}^{2+}$ & $\mathrm{Ni}^{2+}$ & $\mathrm{Zn}^{2+}$ & $\mathrm{Pb}^{2+}$ & $\mathrm{Hg}^{2+}$ & $\mathrm{Cu}^{2+}$ & $\mathrm{Ni}^{2+}$ & $\mathrm{Zn}^{2+}$ & $\mathrm{Pb}^{2+}$ & $\mathrm{Hg}^{2+}$ & $\mathrm{Cu}^{2+}$ & $\mathrm{Ni}^{2+}$ & $\mathrm{Zn}^{2+}$ & $\mathrm{Pb}^{2+}$ & $\mathrm{Hg}^{2+}$ \\
\hline Guar gum & - & - & 2.9 & 2.1 & 1.1 & 2.2 & 1.2 & 14.9 & 10.5 & 5.8 & 11.2 & 6.2 & 1.4 & 1.0 & 0.6 & 1.1 & 0.6 \\
\hline Guar gum-g-ACM-1 & 9 & 58.1 & 3.7 & 2.9 & 2.1 & 2.6 & 1.6 & 19.4 & 14.8 & 10.7 & 13.2 & 8.3 & 1.8 & 1.4 & 1.1 & 1.3 & 0.8 \\
\hline Guar gum-g-ACM-2 & 17 & 80.5 & 5.4 & 4.3 & 3.4 & 3.9 & 2.2 & 28.5 & 22.6 & 17.7 & 20.7 & 11.5 & 2.6 & 2.1 & 1.8 & 2.0 & 1.1 \\
\hline Guar gum-g-ACM-3 & 25 & 143.5 & 8.3 & 7.8 & 5.3 & 7.1 & 4.3 & 45.2 & 42.4 & 28.1 & 38.5 & 22.4 & 4.0 & 3.8 & 2.8 & 3.6 & 2.1 \\
\hline Guar gum-g-ACM-4 & 33 & 165.4 & 11.4 & 10.5 & 9.5 & 9.9 & 6.7 & 64.4 & 58.6 & 52.5 & 55.1 & 36.2 & 5.5 & 5.1 & 5.0 & 5.0 & 3.3 \\
\hline Guar gum-g-ACM-5 & 41 & 189.4 & 13.9 & 11.9 & 10.6 & 11.3 & 8.6 & 80.7 & 67.8 & 59.6 & 63.8 & 46.9 & 6.7 & 5.8 & 5.6 & 5.7 & 4.2 \\
\hline
\end{tabular}

$[$ Guar gum $]=1.0 \mathrm{~g} / \mathrm{dm}^{3} ;\left[\mathrm{V}^{+5}\right]=1.4 \times 10^{-2} \mathrm{~mol} / \mathrm{dm}^{3} ;[\mathrm{MA}]=12 \times 10^{-3} \mathrm{~mol} / \mathrm{dm}^{3} ;\left[\mathrm{H}^{+}\right]=6.0 \times 10^{-3} \mathrm{~mol} / \mathrm{dm}^{3} ; \mathrm{time}$ $=120 \mathrm{~min}$; temperature $=40^{\circ} \mathrm{C}$.

measured by the turbidity value of the supernatant liquid. Plots of polymer dosage versus supernatant turbidity for noncoking coals are presented in Figure 6. The grafted copolymer (guar gum-gpolyACM) showed better performance with low turbidity than the guar gum backbone. In guar gum$g$-polyACM, the hanging of polyACM chains had better accessibility to the contaminant coal particles, which increased its flocculation potential. Here the bridging mechanism operated, which involved the binding or bridging of individual particles with polyACM more than guar gum, and formed good flocs; hence, its flocculation potential increased. By grafting poly(ACM) onto guar gum, we obtained efficient flocculants that may be used for the treatment of coal wastewater.

Intrinsic viscosity $([\eta])$ and reduced viscosity

If two polymers have more or less equal molecular weight, a branched polymer's hydrodynamic volume will be lower, and hence, it will have a lower [ $\eta]$ compared to its linear polymer. The longer the branches are, the higher [ $\eta]$ will be and vice versa; the same was observed during our experiment. In this series of graft copolymers (GOH-g-ACM-1 to GOH-g-ACM-5), the value of [ $\eta$ ] gradually increased. The $[\eta]$ value of $\mathrm{GOH}-\mathrm{g}-\mathrm{ACM}-3$ was higher because of the presence of longer ACM chains. The concentration of ACM in GOH-g-ACM-4 was higher than that of GOH-g-ACM-1; because of this, [ $\eta]$ of the former was higher than that of the latter. However, $[\eta]$ of GOH-g-ACM-3 was higher than that of GOH-g-ACM-2, which indicated that GOH-g-ACM-3 contained longer PolyACM chains than GOH-g-ACM-2. The [ $\eta]$ values of all of the graft copolymers are summarized in Table V. [ $\eta]$ of $\mathrm{GOH}$ was $2.3 \mathrm{dL} / \mathrm{g}$, This result was consistent with the value observed by Gómez Díaz et al. ${ }^{33}[\eta]$ plots of $\mathrm{GOH}$ and grafted polyACM are shown in Figure 7.

\section{Calculation of the approximate molecular weight}

The molecular weights of the polymer samples were calculated from the $[\eta]$ values. The Mark-Houwink equation $\left([\eta]=K M^{\alpha}\right.$, where $K$ and $\alpha$ are constants for a given polymer/solvent/temperature system and $M$ is the molecular weight) was used to calculate the molecular weights of the polymers. For poly$\mathrm{ACM}$, the values of $K$ and $\alpha$ are given next ${ }^{33}$ :

$$
\begin{gathered}
{[\eta]=6.8 \times 10^{-4}\left(M_{n}\right)^{0.66}} \\
{[\eta]=6.31 \times 10^{-5}\left(M_{w}\right)^{0.80}}
\end{gathered}
$$

where $M_{n}$ is the number-average molecular weight and $M_{w}$ is the weight-average molecular weight.

The graft copolymers were synthesized as reported previously. Moreover, the percentage of polysaccharide was small in comparison with that of polyACM. Hence, in case of the grafted polysaccharides, several authors ${ }^{34-37}$ have used the MarkHouwink equation, which is applicable for linear polymers, to estimate approximate molecular weights. The same was done in this case. The

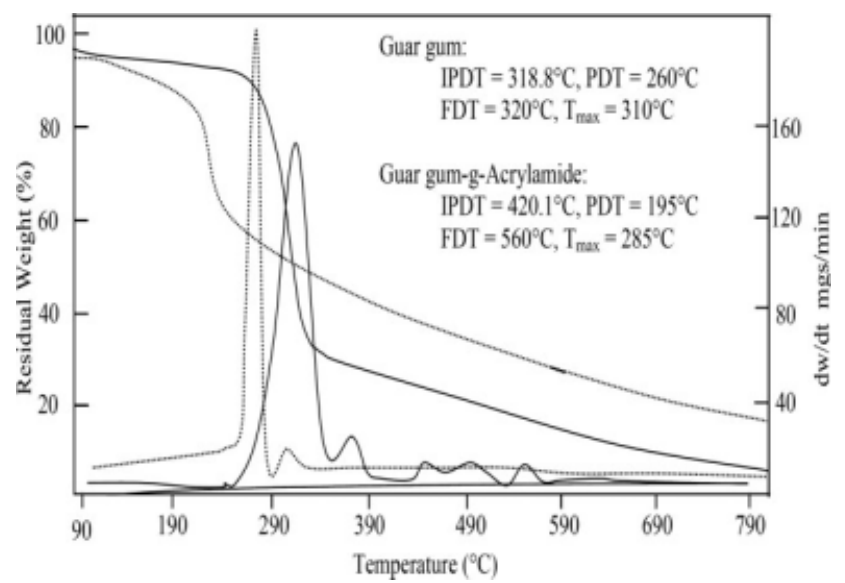

Figure 8 Thermogravimetric traces of $(\cdots)$ guar gum and (-) guar gum-g-ACM. 
TABLE VII

Decomposition Temperatures of the Ungrafted and Grafted Guar Gum

\begin{tabular}{|c|c|c|c|c|c|c|c|c|}
\hline & \multicolumn{8}{|c|}{ Decomposition temperature $\left({ }^{\circ} \mathrm{C}\right)$} \\
\hline & $\begin{array}{c}10 \% \\
\text { weight } \\
\text { loss }\end{array}$ & $\begin{array}{c}20 \% \\
\text { weight } \\
\text { loss }\end{array}$ & $\begin{array}{c}30 \% \\
\text { weight } \\
\text { loss }\end{array}$ & $\begin{array}{c}40 \% \\
\text { weight } \\
\text { loss }\end{array}$ & $\begin{array}{c}50 \% \\
\text { weight } \\
\text { loss }\end{array}$ & $\begin{array}{c}60 \% \\
\text { weight } \\
\text { loss }\end{array}$ & $\begin{array}{c}70 \% \\
\text { weight } \\
\text { loss }\end{array}$ & $\begin{array}{c}75 \% \\
\text { weight } \\
\text { loss }\end{array}$ \\
\hline Guar gum & 262 & 286 & 296 & 300 & 306 & 314 & 348 & 400 \\
\hline Guar gum-g-ACM & 150 & 190 & 200 & 250 & 318 & 440 & 550 & 685 \\
\hline
\end{tabular}

approximate molecular weights of the graft copolymers are given in Table $\mathrm{V}$.

\section{Metal-ion sorption}

The results of the sorption behavior of guar gum and its grafted polymer with ACM were determined in terms of the percentage ion uptake, partition coefficient, and retention capacity. The values of the percentage ion uptake, partition coefficient, and retention capacity increased directly as the percentage grafting increased (the results are given in Table VI), which might have been due to the increase in pendent chains of polyACM. The results also show that $\mathrm{Hg}^{2+}$ was least absorbed in comparison to four other metal ions. The strength of unabsorbed metal ions was determined by a standard method. ${ }^{26}$ For metalion sorption studies, we chose five metal ions: $\mathrm{Cu}$, $\mathrm{Ni}, \mathrm{Zn}, \mathrm{Pb}$, and $\mathrm{Hg}$. The sorption behavior of the polymeric backbone and graft copolymer for the five metals ions was investigated with the following parameters $^{27}$ :

Percent uptake

$$
=\frac{\text { Amount of metal ion in the polymer }}{\text { Amount of metal ion in the feed }} \times 100
$$

Partion coefficent

$$
\begin{aligned}
& =\frac{\text { Amount of metal ion in the polymer }}{\text { Amount of metal ion left in the solution }} \\
& \qquad \times \frac{\text { Volume of solution }(\mathrm{ml})}{\text { weight of dry polymer }}
\end{aligned}
$$

Retention capacity

$=\frac{\text { Amount of metal ion in the polymer mequiv }}{\text { Weight of dry polymer }(\mathrm{g})} \times 100$

TABLE VIII

Thermogravimetric Analysis of the Ungrafted and Grafted Guar Gum

\begin{tabular}{lcccc}
\hline \multicolumn{1}{c}{ Sample } & $\operatorname{PDT}\left({ }^{\circ} \mathrm{C}\right)$ & $\mathrm{FDT}\left({ }^{\circ} \mathrm{C}\right)$ & $\mathrm{IPDT}\left({ }^{\circ} \mathrm{C}\right)$ & $T_{\max }\left({ }^{\circ} \mathrm{C}\right)$ \\
\hline Guar gum & 260.0 & 320.0 & 318.8 & 310.0 \\
Guar gum-g-ACM & 195.0 & 560.0 & 420.1 & 285.0 \\
\hline
\end{tabular}

Thermogravimetric analysis

Guar gum. The thermogram of guar gum (the dotted curve in Fig. 8) revealed that the decomposition of guar gum started at $230^{\circ} \mathrm{C}$, and it was a single-step degradation process. The rate of weight loss increased with increasing temperature up to $310^{\circ} \mathrm{C}$; thereafter, rate of weight loss decreased. About $68 \%$ weight loss occurred between 200 and $400^{\circ} \mathrm{C}$, and only a $5 \%$ char yield was obtained at $800^{\circ} \mathrm{C}$. Nearly $75 \%$ of the guar gum degraded at $400^{\circ} \mathrm{C}$ (shown in Tables VII and IX). Therefore, the final decomposition temperature (FDT) was at a very low temperature, that is, $320^{\circ} \mathrm{C}$. The polymer decomposition temperature (PDT), temperature at which maximum degradation occurred $\left(T_{\max }\right)$, and integral procedural decomposition temperature (IPDT) of the guar gum were 260,310 , and $318.8^{\circ} \mathrm{C}$, respectively (Table VIII). The degradation of guar gum was quite complex and started with depolymerization through random chain scission associated with degradation followed by molecular rearrangement.

Guar gum-g-ACM. The degradation of guar gum-gACM started above $180^{\circ} \mathrm{C}$; however, $10 \%$ weight loss was observed at $90^{\circ} \mathrm{C}$, which was attributed to the absorbed water. The rate of weight loss increased with increasing temperature from 110 to $210^{\circ} \mathrm{C}$ but gradually decreased above this temperature (the solid curve in Fig. 8). About 57\% weight loss was observed in the temperature range $200-400^{\circ} \mathrm{C}$ (Table VII), and a char yield of $18 \%$ was obtained at $710^{\circ} \mathrm{C}$. The degradation occurred in two stages, that is, from 150 to $177^{\circ} \mathrm{C}$ and from 177 to $530^{\circ} \mathrm{C}$. The maximum weight loss (i.e., the weight loss at $T_{\max }$ ) appeared at $285^{\circ} \mathrm{C}$, and this may have been due to the elimination of the $\mathrm{NH}_{3}$ molecule from the grafted chain of polyACM. The PDT, FDT, and IPDT values of guar gum-g-ACM were obtained at 195,560 , and $420^{\circ} \mathrm{C}$, respectively (Table VIII). The decomposition temperature of guar gum and guar gum-g-ACM was the same up to $50 \%$ weight loss (Tables VII and IX). Beyond 50\% weight loss, the grafted guar gum showed a much higher decomposition temperature than guar gum. The higher values of PDT, FDT, IPDT, and $T_{\max }$ of the grafted guar gum compared to those of guar gum indicated an overall improvement in the thermal stability of the graft copolymer. 
TABLE IX

Weight Losses of the Ungrafted and Grafted Guar Gum at Different Temperatures

\begin{tabular}{lcccccccc}
\hline & \multicolumn{7}{c}{ Weight loss (\%) } \\
\cline { 2 - 8 } & $100^{\circ} \mathrm{C}$ & $200^{\circ} \mathrm{C}$ & $300^{\circ} \mathrm{C}$ & $400^{\circ} \mathrm{C}$ & $500^{\circ} \mathrm{C}$ & $600^{\circ} \mathrm{C}$ & $700^{\circ} \mathrm{C}$ & $800^{\circ} \mathrm{C}$ \\
\hline Guar gum & 3 & 7 & 35 & 75 & 81 & 88 & 92 & 95 \\
Guar gum-g-ACM & 5 & 30 & 47 & 57 & 65 & 77 & 81 & - \\
\hline
\end{tabular}

\section{CONCLUSIONS}

- Guar gum-g-ACM was successfully synthesized with an efficient redox initiator, that is, vana$\operatorname{dium} / \mathrm{MA}$ in an inert atmosphere. From the results of our study, we concluded that minimum concentrations for the redox pair of $6.0 \times$ $10^{-3}$ for $\mathrm{V}^{5+}$ and $2.0 \times 10^{-3} \mathrm{~mol} / \mathrm{dm}^{3}$ for MA were sufficient for the maximum percentage of grafting, which also supported the efficiency of the redox pair.

- In this synthesis, $\mathrm{H}^{+}$ion concentration played an important role in the values of the grafting parameters.

- The swelling study showed that the grafted polyACM chain increased the water absorption capacity of the polymer backbone.

- The spectroscopic study proved the grafting of the monomer on the $\mathrm{O}-\mathrm{H}$ site of the backbone; this also supported the proposed mechanism.

- During the reaction, the radical that was formed was incorporated in the graft copolymer start chain; because of this, the graft copolymer contained amide, carboxylic acid, and alcoholic groups. Thus, a multifunctional graft copolymer was formed, which may have had better properties than other reported graft copolymers of guar gum-g-ACM because of its acidic, basic, and alcoholic groups.

- The higher values of FDT, IPDT, and char yield supported the increased thermal stability of the graft copolymer.

\section{References}

1. Dixon, J. K. In Encyclopedia of Polymer Science and Technology; Mark, H. F.; Gaylord, N. G.; Bikales, N. M., Eds.; Interscience: New York, 1967; Vol. 7, p 64.

2. Gurruchaga, M.; Goni, I.; Valero, M.; Guzman, G. M. Polymer 1992, 33, 3274.

3. Singh, O. P.; Sandle, N. K.; Varma, I. K. Angew Makromol Chem 1984, 121, 187.

4. Cai, Z.; Wang, Z.; Pan, S. Zhongguo Zaozhi 1990, 9, 37.

5. Ranby, B.; Zuchowska, D. Polym J 1987, 19, 623.

6. Wu, G.; Yanxia, S.; Qhing, L; Zhang, G. Jilin Daxue Ziran Kexue Xuebao 1988, 3, 123.

7. Deshmukh, S. R.; Chaturvedi, P. N.; Singh, R. P. J Appl Polym Sci 1985, 30, 4013.
8. Deshmukh, S. R.; Singh, R. P. J Appl Polym Sci 1987, 33, 1963.

9. Seaman, J. K. Handbook of Water-Soluble Gums and Resins; McGraw-Hill: New York, 1980; p 6.

10. Goldstein, A. M.; Alter, E. N.; Seaman, J. K. Industrial Gum, 2nd ed.; Academic: New York, 1973; Chapter 14, p 303.

11. Werbin, S. J. U.S. Pat. 2,502,397 (1950); Chem Abstr 1950, 44, 5496 .

12. Krishnaiah, Y. S. R.; Karthikeyen, R. S.; Gouri, S. V.; Satyanarayan, V. J Controlled Release 2002, 81, 45.

13. Sakai, T. K. M.; Uzuhashi, Y. Jpn Kokai Tokkyo Koho JP 125714 (2003); Chem Abstr 2003, 138, 358461r.

14. Harle, D.; Wang, S.; Green, R. C. PCT Int. Pat. 2365505 (2003); Chem Abstr 2003, 139, 70660c.

15. Saalfrank, A.; Pfeifer, P. Naturwissenschaffen Unterricht Chem 2002, 13, 18.

16. Whistler, R. L. Industrial Gum; Academic: New York, 1973; p 6.

17. Panday, P. K.; Srivastava, A.; Tripathy, J.; Behari, K. Carbohydr Polym 2006, 65, 414.

18. Kumar, R.; Srivastava, A.; Behari, K. J Appl Polym Sci 2008, 107, 2883.

19. Sharma, B. J.; Kumar, V.; Soni, P. L. Trends Carbohydr Chem 1999, 5, 75.

20. Wunderlich, T.; Stelter, M.; Tripathy, T.; Nayak, B. R.; Brenn, G.; Yarin, A. L.; Singh, R. P.; Brunn, P. O.; Durst, F. J Appl Polym Sci 2000, 77, 3200.

21. Behari, K.; Taunk, K.; Tripathi, M. J Appl Polym Sci 1999, 71, 739.

22. Kanus, S.; Spaotjaric-Lukacic, L.; Lisa, L.; Saf, R. Eur Polym J 2005, 41, 2240.

23. Fanta, G. F. In Block and Graft Copolymerization; Ceresa, R. J., Ed.; Wiley-Interscience: New York, 1973; p 1.

24. Mohanty, E.; Singh, B. C. J Appl Polym Sci 1998, 69, 2569.

25. El-Rehim Abd, H. A.; El-Sayed, A. H.; Ali, A. M. J Appl Polym Sci 2000, 76, 125.

26. Basset, J.; Denny, R. C.; Jeffery, G. H.; Mendham, J. Vogel's Text Book of Quantitative Analysis, 4th ed.; William Clowes and Sons: London, 1978; p 324.

27. Rivas, B. L.; Maturana, H. A.; Molina, M. J.; Gomez-Anton, M. R.; Pierola, I. F. J Appl Polym Sci 1998, 67, 1109.

28. Nayak, B. R.; Singh, R. P. J Appl Polym Sci 2001, 81, 1776.

29. Littler, J. S.; Waters, W. A. J Chem Soc 1959, 1299.

30. Nayak, P. L.; Samal, R. K.; Nayak, M. C. Angew Macromol Chem 1979, 80, 95.

31. Samal, R. K.; Nanda, C. N.; Satrusallya, S. C.; Nayak, B. L.; Suryanarayan, G. V. J Appl Polym Sci 1983, 28, 1311.

32. Pourjavadi, A.; Mahdavinia, G. R. Turk J Chem 2006, 30, 595.

33. Gómez-Díaz, D.; Navaza, J. M. Electron J Environ Agric Food Chem 2002, 1, 1579.

34. Erciyes, A. T.; Erim, M.; Hazer, B.; Yagci, Y. Angew Macromol Chem 1992, 200, 163.

35. Tripathy, T.; Karmakar, N. C.; Singh, R. P. Int J Polym Mater $2000,46,81$.

36. Swarson, C. L.; Shogren, R. L.; Fanta, G. F.; Imam, S. H. J Environ Polym Degrad 1993, 1, 155.

37. Hartley, F. D. J Polym Sci 1959, 34, 397. 